\title{
The climate changes in the sub-basin of the Oum Er rbia central and the impact on the surface waters.
}

\author{
Zhour Echakraoui ${ }^{\text {}}$, *, Ahmed. Boukdir ${ }^{1}$, Olaide. Aderoju ${ }^{2}$, El Hassan Ben - Saïd ${ }^{1}$, \\ Abdelhamid. Zitouni ${ }^{1}$, Rachid El maslouhi ${ }^{3}$ and António Guerner Dias ${ }^{2}$ \\ ${ }^{1}$ University Sultane Moulay Slimane, Faculty of Sciences and Technology, Laboratory of Industrial \\ Engineering, Beni Mellal, Morocco \\ ${ }^{2}$ University of Porto, Faculty of Sciences and Technology, Department of Geosciences, Environment \\ and Spatial Planning \\ ${ }^{3}$ OumEr Rbia Hydraulic Basin Agency, Morocco
}

\begin{abstract}
Observations and model results indicate that climate trends in North Africa show both drying and warming over the past few decades, according to the latest Intergovernmental Panel on Climate Change (IPCC) assessment. During the last decades, due to changes in climatic and environmental conditions, water resources available in Morocco are decreasing. They are, moreover, subject to extreme cyclical variations and to soaring water demands because of rapid population growth, improvement of living standards, industrial development and expansion of irrigated agriculture. The pressure on these water resources is accompanied by a growing and increasingly serious degradation of their quality. This is found at the level of average of air temperatures that are continuously growing and at the level of precipitation with an average potential of water in the area with a significant decrease in the last forty years.
\end{abstract}

The purpose of this work is to make a study on the impact of climate change on water resources that exist in the basin of the Oum Er Rbia Central, and to give justifiable results regarding the evolution of climate change over time. From the created database, we brought out diagrams, curves and maps of the evolution of climate change that show the results below:

The study of the evolution of rainfall recorded since 1934 and the breaks in time series highlighted two methodologically distinct periods: a wet period with high rainfall (1986 - 1971), a dry season and low rainfall (1970/71 to 2007).

Observed climatic trends, calculated over the period of 1935-2007 and reported in the study, indicate the following:

*Corresponding author: zhourgat@gmail.com 
- On an annual basis, changes in precipitation were not significant and varied from one region to another. On the other hand, spring rainfall declined significantly in the northern part of Morocco at a rate of $0.5 \mathrm{~mm} /$ day per decade;

- That the area experienced an average annual rainfall reduction of 70 $\mathrm{mm}(20 \%)$ over this period compared to 1940-1980. The area is a hydraulic region that is already experiencing a water deficit. The sharp decline in water supplies since 1980-2007 (by 40\% compared with 19401980) and the increase in demand and water degradation by different causes;

- The annual average flows measured at the the central Oum Er Rbia stations were reduced by considerable hydrological deficits ranging between 40.8 and $49.5 \%$.

Global warming and rainfall regression are added to the intrinsic conditions of sub basins of the Oum Er Rbia Central (especially waterproofing of land and the lack of groundwater reservoir) to increase its vulnerability to water scarcity. This critical situation requires adapting good management methods of meteorological water as the only source of water in this basin. You should leave $8 \mathrm{~mm}$ of space above the abstract and $10 \mathrm{~mm}$ after the abstract. The heading Abstract should be typed in bold 9point Arial. The body of the abstract should be typed in normal 9-point Times in a single paragraph, immediately following the heading. The text should be set to 1 line spacing. The abstract should be centred across the page, indented $17 \mathrm{~mm}$ from the left and right page margins and justified. It should not normally exceed 200 words. 


\section{Introduction}

Climate change has become progressively more widespread since the Rio conference in 1992, when the world's countries recognized this danger. At this conference is launched the United Nations Framework Convention on Climate Change. These countries were committed to addressing this climate change through the mitigation of GHG emissions and by adapting development policies and programs to limit the negative impacts that could result from global warming.

Each of the last three decades has been successively warmer on the Earth's surface than any previous decade since 1850 . The years 1983 to 2012 are probably the warmest 30-year period in the northern hemisphere in the last 1400 Years (average confidence). The linear trend in the global average of surface temperature data combining land and oceans indicates a warming of $0.85^{\circ} \mathrm{C}$ over the period of $1880-2012$ (IPCC 2014).

Observations and model results indicate that climate trends in North Africa show both drying and warming over the past few decades. According to the latest Intergovernmental Panel on Climate Change (IPCC) assessment, the region's climate is projected to become even hotter and drier in the next century, which will expose additional millions of people to further water stress. It is projected that climate change would likely increase the pressure on the already over-exploited surface and groundwater resources. With the added complexity of population growth, economic growth, the potential for increasing frequency of heat waves, and declining snow-packs, Morocco's water scarcity problem is likely to amplify in the future.

The climate change is confirmed with strong impacts notably on the water cycle. This is particularly true in the Mediterranean and in Africa where this warming is important and where the impact on water resources accentuates and accelerates the supply-demand deficit that many countries in the region are experiencing, logically with a strong growth in demand for water, pressure on water resources Countries in recent decades.

In Morocco, the trend towards global warming has been confirmed, also with the intraannual and interannual irregularity of precipitation that has been in place since the 1970s and more extreme events, with consequence in dysregulation of the seasonal cycle. To address this situation and its impact on the water sector in Morocco, commendable efforts have been made, with a reinforced dams policy, structured and organized water management planning and adaptive measures and actions, have been more reactive than preventive.

Today, 30 years after the first signs of the hydro-climatic problem experienced during the droughts of the 1980s, this instability / irregularity of the climate reached a threshold whose impact on the management of water resources no longer allows to be considered without adequate planning and anticipation. There is a clear need to integrate this climate change in a structural way and its possible effects on water management in the country, both in policy choices for water use and in the implementation of these policies. 


\section{Geographic location and presentation of the watershed}

\subsection{Physical characteristics the Oum Er Rbia area}

The Oum Er Rbia Basin is one of the Kingdom's largest basins. It spreads over an area of $35000 \mathrm{~km} 2$ with an extension of $550 \mathrm{~km}$. The river Oum Er Rbia originates in the Middle Atlas at $1,800 \mathrm{~m}$ of altitude to $40 \mathrm{~km}$ of the city of Khénifra and to $26 \mathrm{~km}$ Of the town of M'Rirt and crosses the chain of the Middle Atlas, the plain of Tadla and the Coastal Meseta before sinking in the Atlantic Ocean to $16 \mathrm{~km}$ of the city of El Jadida. It has a length of about $600 \mathrm{~km}$.

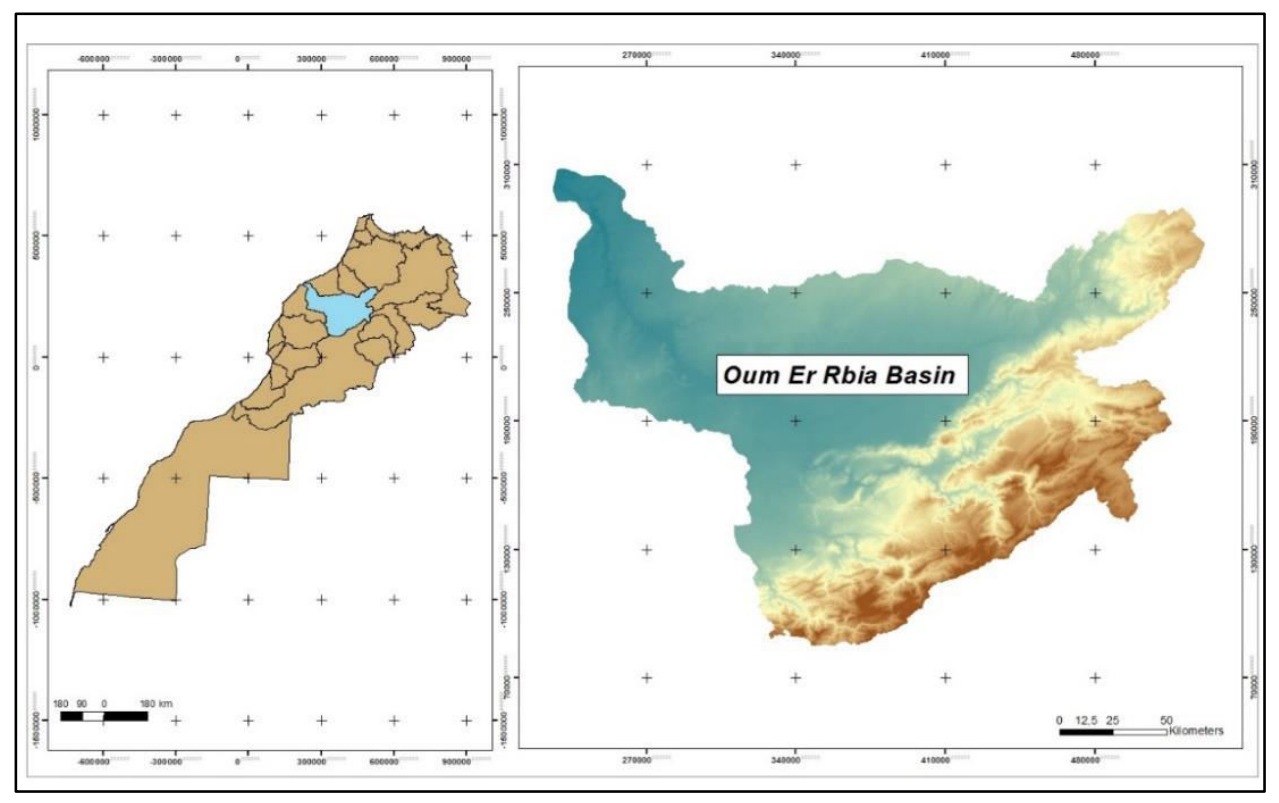

Fig. 1. Location of the Oum Er Rbia basin

The hydrographic network of the basin is formed by the Oued Oum Er Rbia and its tributaries: Tassaout, El Abid, Lakhdar, Derna, Melloul, Ouamana, Srou, Chbouka, Ouirine, Gzef, El Touim and Faragh. Thanks to rainfall varying from $300 \mathrm{~mm}$ to $1100 \mathrm{~mm}$, the average supply at the mouth of the Oum Er Rbia river is significant and is estimated at 3 $680 \mathrm{Mm} 3$ / year

These contributions come mainly from Oum Er Rbia river and its main tributaries:

- Tassaout;

- Lakhdar;

- $\quad$ El Abid.

The contributions of numerous sources associated with those of the melting of the snow guarantee a very low water level for the Oum Er Rbia making it the most regular course of the Kingdom. 
Average inputs in this zone are estimated at 3,730 Mm3 / year with a maximum of 8,300 $\mathrm{Mm} 3$ / year and a minimum of 1,300 Mm3 / year.

The area includes a mobilizable water potential of 4,000 Mm3 of which 3,365 Mm3 are already mobilized.

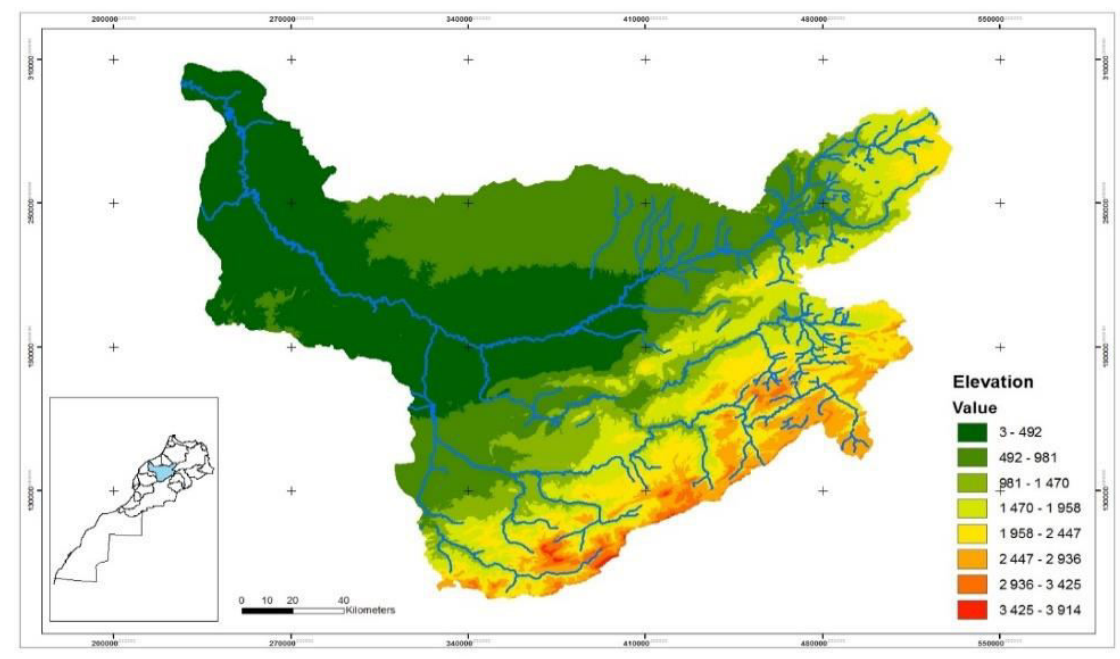

Fig. 2. River systems in Oum Er Rbia basin

The climate in the basin is arid to semi-arid, with decreasing precipitation from West to East (1100 to $250 \mathrm{~mm} /$ year). However, in the upstream portion of the basin, at the high altitude of the Atlas Mountains, the annual rainfall may reach $1000 \mathrm{~mm}$, with a significant amount of snowfall at altitudes above $1500 \mathrm{~m}$.

The average rainfall in the basin is about $500 \mathrm{~mm} /$ year and varies between $1100 \mathrm{~mm}$ in the Middle Atlas and $300 \mathrm{~mm}$ in the area downstream of the River basin. The temperature varies between 10 and $50{ }^{\circ} \mathrm{C}$. The lowest and highest temperatures are $3.5^{\circ} \mathrm{C}$ in January and $38^{\circ} \mathrm{C}$ in August.

Potential Evaporation can reach 1600 to $1800 \mathrm{~mm} /$ year. On the average, it is about 1600 $\mathrm{mm}$ per year in the coastal area and $2000 \mathrm{~mm}$ within the basin with a monthly maximum of $300 \mathrm{~mm}$ in July and August.

Most of the basin water resources are generated in the High Atlas Mountains, upstream of the basin. The hydrological network consists of the main river, the Oum Er Rbia $(550 \mathrm{~km})$, with three mains tributaries: the Tessaout River, the Lakhdar River, and El Abid River. The annual average flows of the river basin are estimated to 3,250 Mm3/year with a maximum of $8,300 \mathrm{Mm} 3$ and a minimum of 1,300 Mm3.The title is set in bold 16-point Arial, justified. The first letter of the title should be capitalised with the rest in lower case. You should leave $22 \mathrm{~mm}$ of space above the title and $6 \mathrm{~mm}$ after the title. 


\subsection{Steps for extracting catchment basin of the Oum Er Rbia basin}

The extraction of the basins in all the cases followed the procedure described by the algorithm of O'Callaghan and Mark (1984). The various steps in this procedure are all functions implemented in Arc / Info-Grid. These different functions were carried on ArcView by the University of Texas team that developed the CRWRPrePro extensions. Detailed descriptions of these procedures are given in Maidment et al. (1997).

Briefly, this sequence of proceedings consists of:

1. Filling of the "wells" of the MNT (FILL): This function locates the closed depressions (either real or created by interpolation during the construction of the MNT) And fills them;

2. calculation of the Mana flow directions;

3. calculation of the rate of accumulation for each of the cells (number of upstream cells;

4. choice of an accumulation threshold for the individualization of the hydrographic network;

5. hydrographic networks from DTM is the individualization of watercourses in flat terrain.

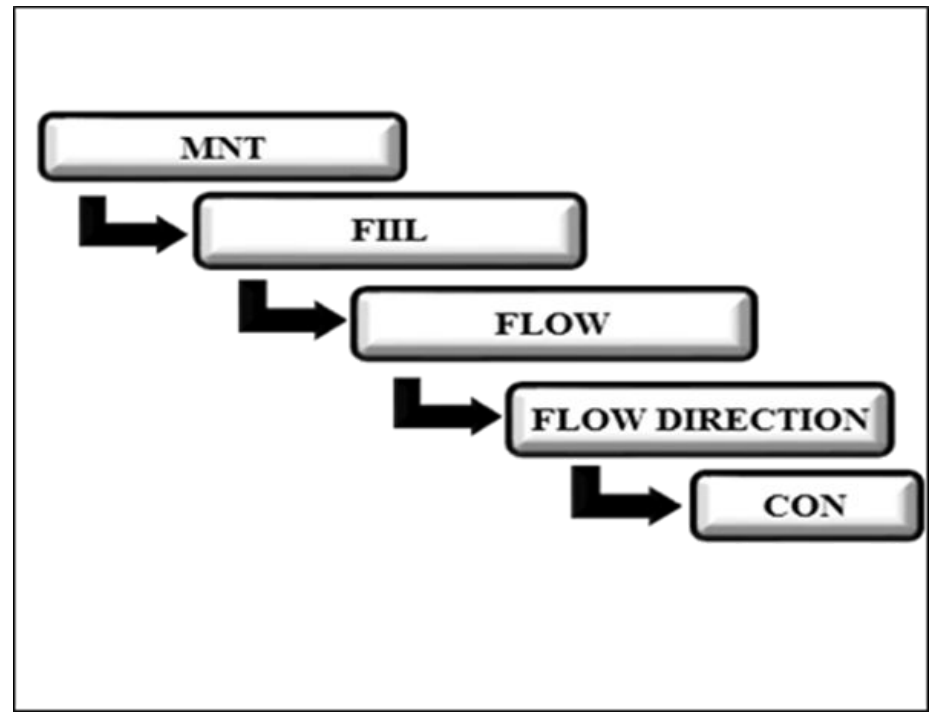

Fig. 3. Extraction steps tributary catchments

Much work has been devoted to this problem and the most commonly adopted solution is to digital terrain model using a pre-existing network. The use of a pre-existing network to allow the automatic extraction of the hydrographic network from a digital terrain model may seem inconsistent. But the modeling objective (and this is the case for many distributed hydrological models using physical bases) requires that a coherent hydrographic network be obtained with a mesh digital topographic basis. (Frédérique Seyler and all).

Table 1. The different sous basins 


\begin{tabular}{|c|c|}
\hline Abbreviation & Sous basins name \\
\hline TS & (Oued Tessaout) \\
\hline HO & (Haut Oum Er Rbia) \\
\hline AB & (Oued El Abid) \\
\hline CO & (Oum Er Rbia central) \\
\hline
\end{tabular}

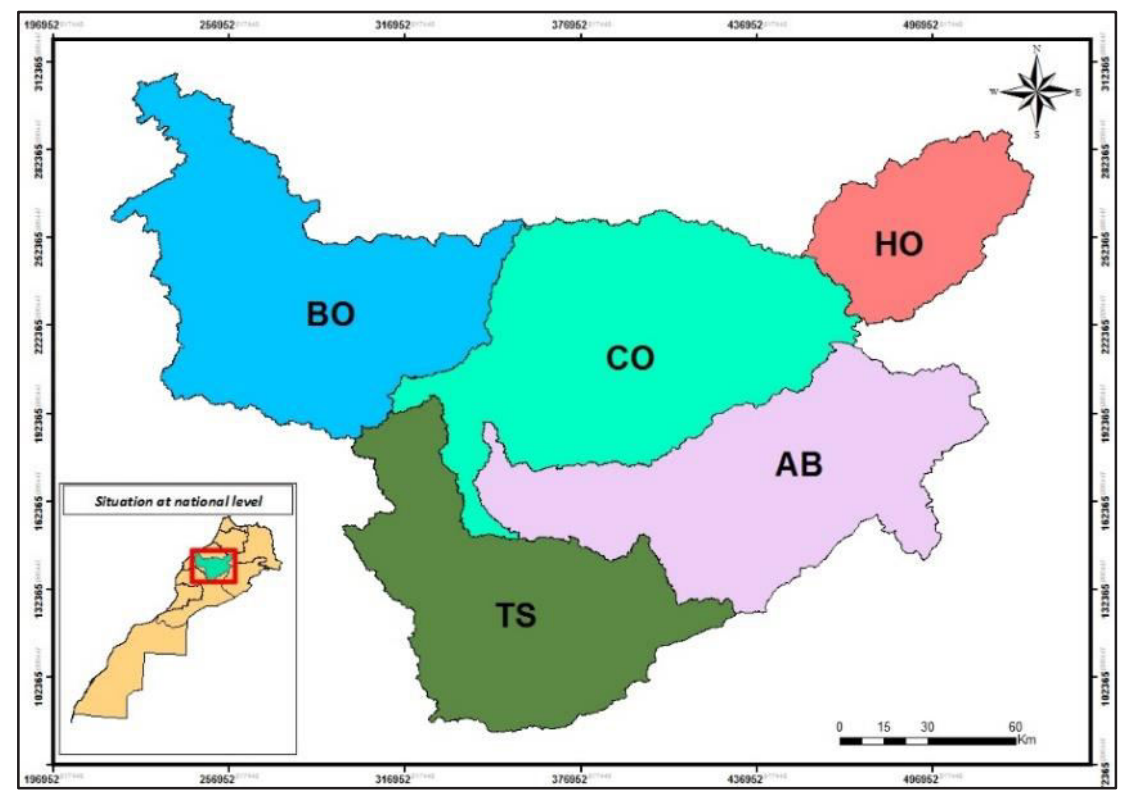

Fig. 4. locations of the 5 tributary catchments in Oum Er Rbia basin 


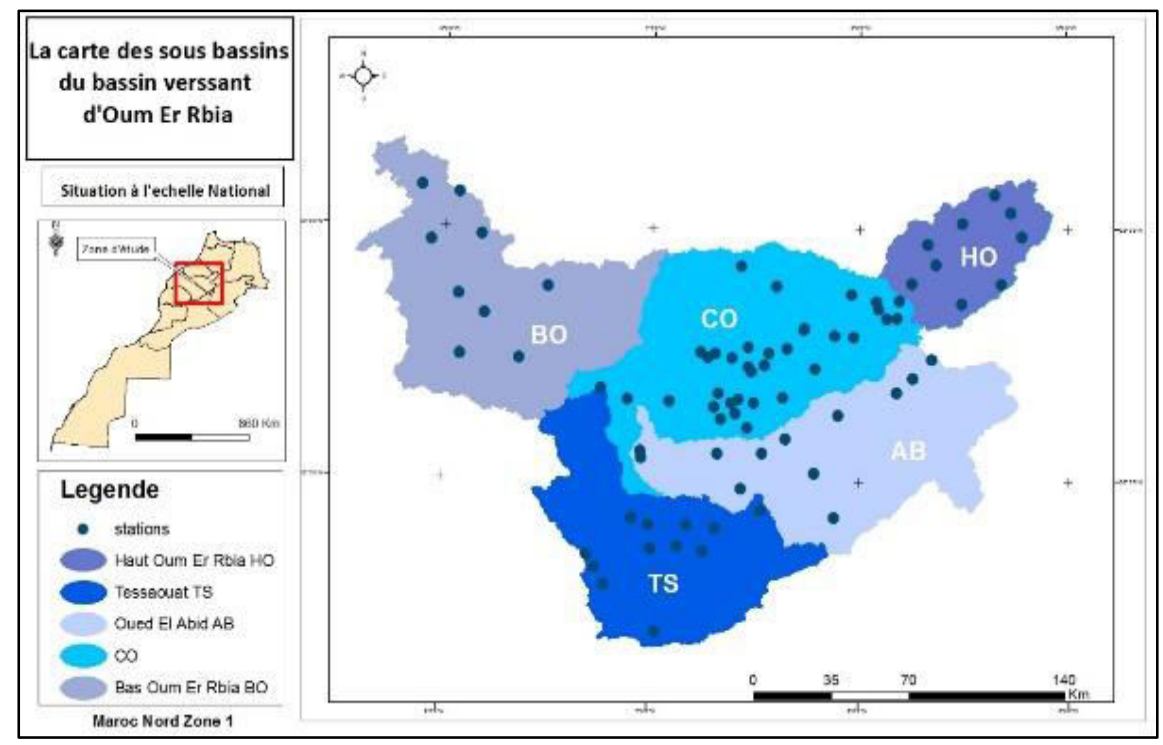

Fig. 5. hydrological and thermal stations in Oum Er Rbia basin

\subsection{Geographic location of the watershed}

So, to facilitate the work, we will choose the basin Oum Er Rbia central for assessment and identify the climate change from the rainfall series.

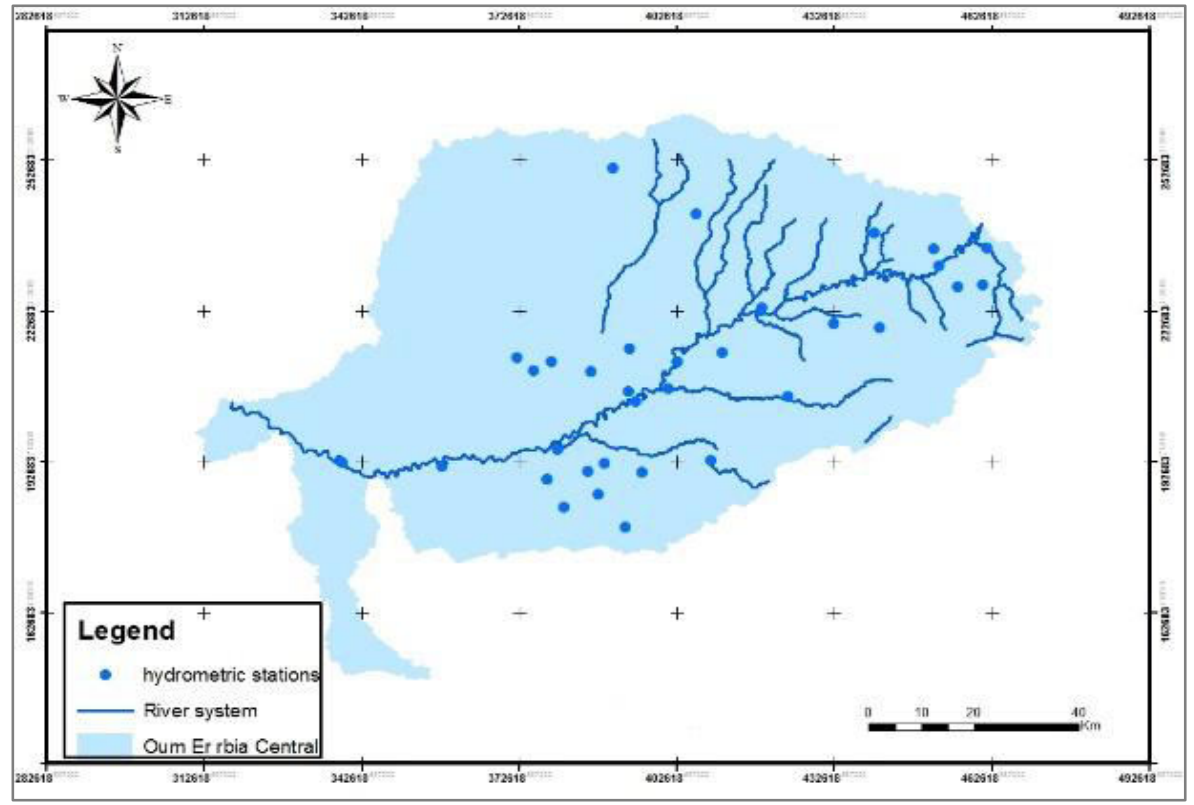

Fig. 6. Geographic location of the basin Oum Er Rbia central 


\section{Data and methods}

\subsection{Data}

The rainfall data collected from the Oum Er Rbia basin agency were basically pre-checked before being supplied to users.

The task aspects studied for this rainfall analysis are presented as follows:

-Data collection, data analysis and review;

-Filling of data;

-The homogenization of rainfall data;

\subsection{Methods}

The analysis of rainfall measured at different meteorological stations is usually carried out in well-defined years (Morel, 1995).

The three criteria for assessing the quality of a rainfall network are:

- The distribution: the network must be spatially homogeneous so as not to favor a region.

- The density: stations must cover the basin from upstream to downstream. For these stations it's important to maintain the interpretations as correct as possible;

- Duration: the choice is made for those with the longest measurement periods (25 to 50 years).

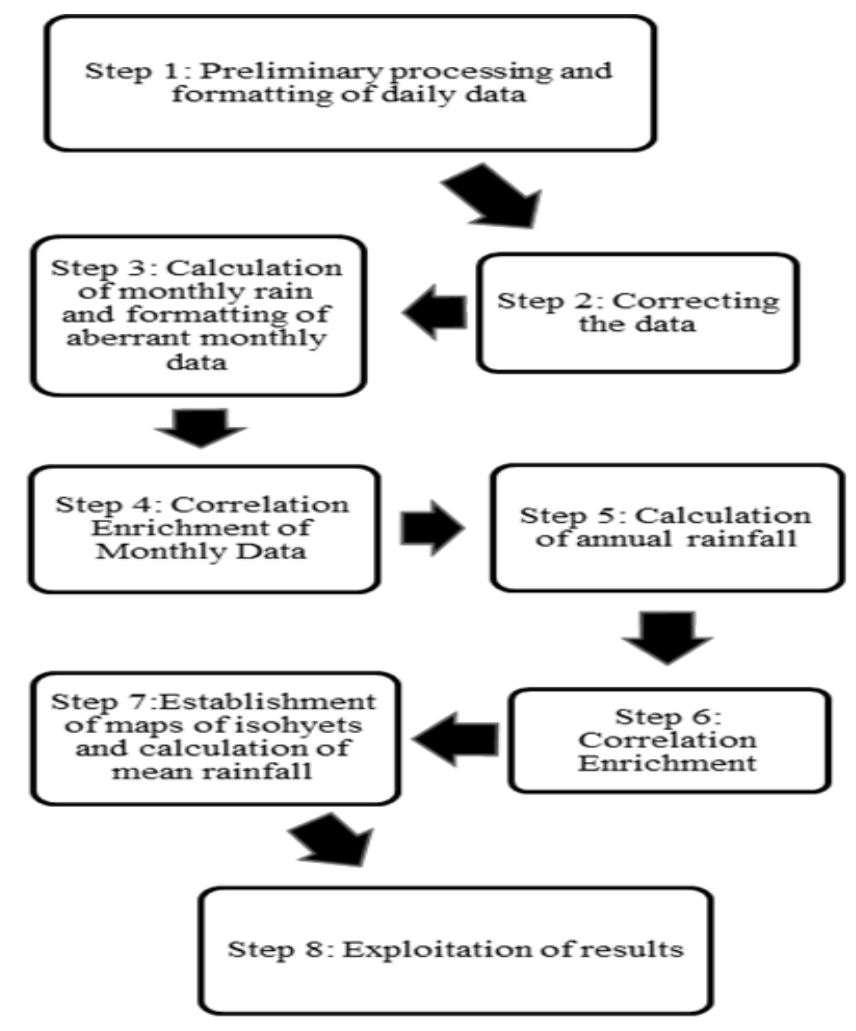

Fig. 7. The analysis of rainfall 


\section{Results}

The results of the analysis of rainfall is presented in graphs below:

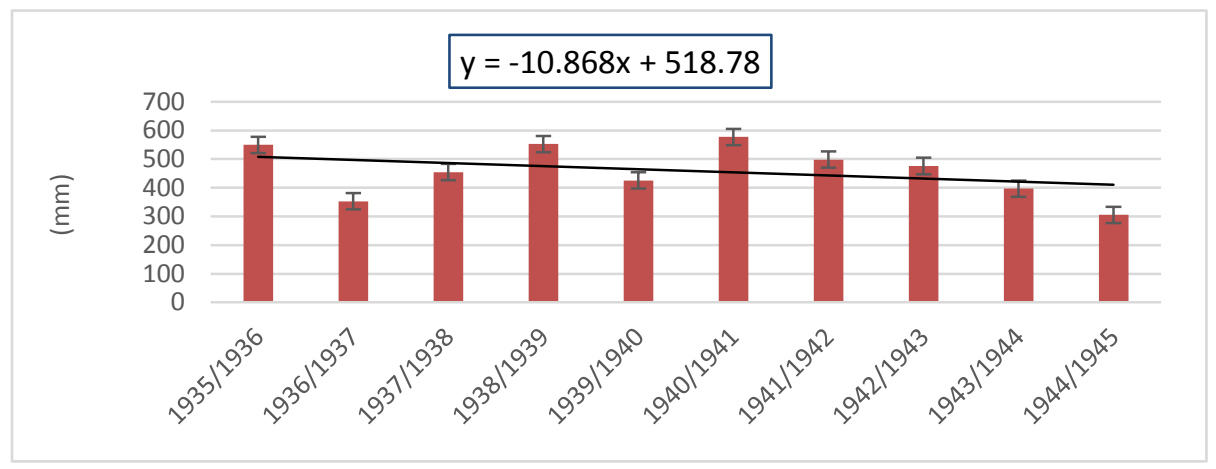

Fig. 8. Evolution of the interannual mean rainfall over the period 1935-1945 of the catchment basin $\mathrm{CO}$

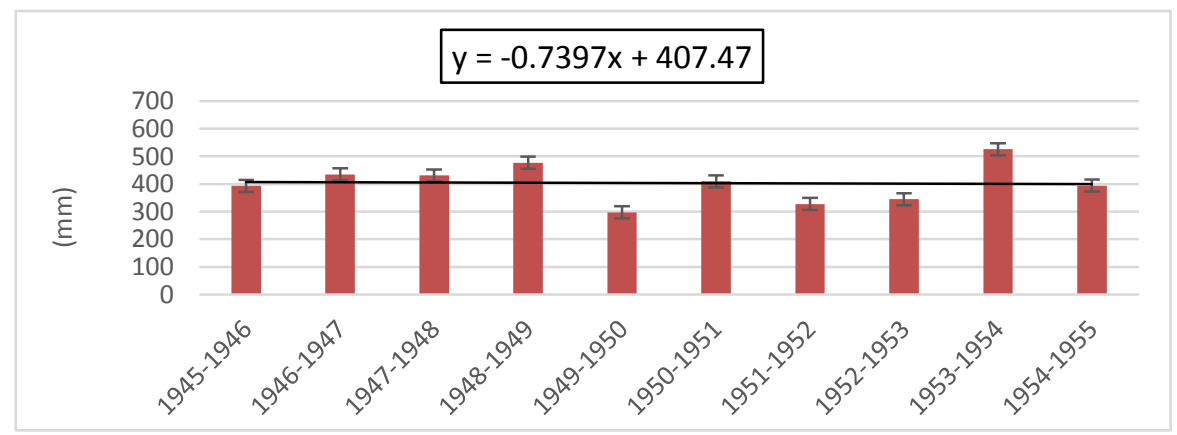

Fig. 9. Evolution of the interannual mean rainfall over the period 1945-1955 of the catchment basin

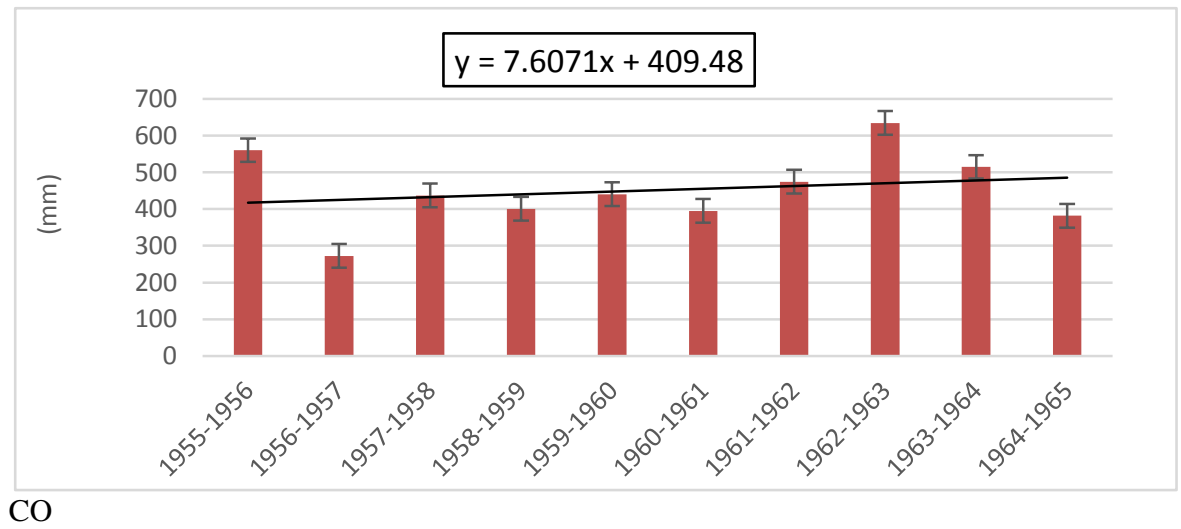


Fig. 10. Evolution of the interannual mean rainfall over the period 1955-1965 of the catchment basin $\mathrm{CO}$

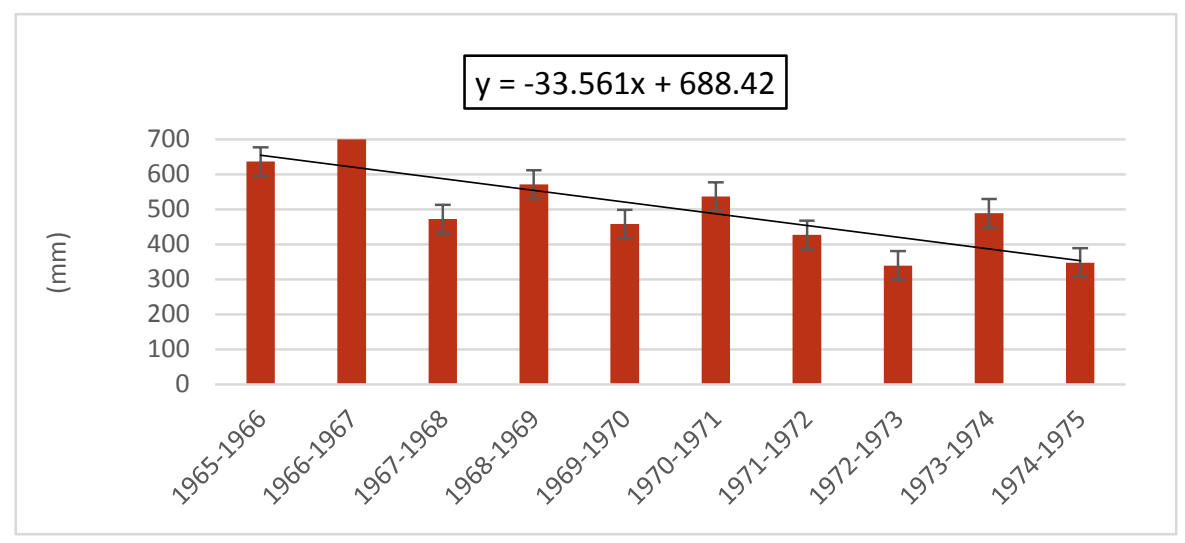

Fig. 11. Evolution of the interannual mean rainfall over the period 1965-1975 of the catchment basin $\mathrm{CO}$

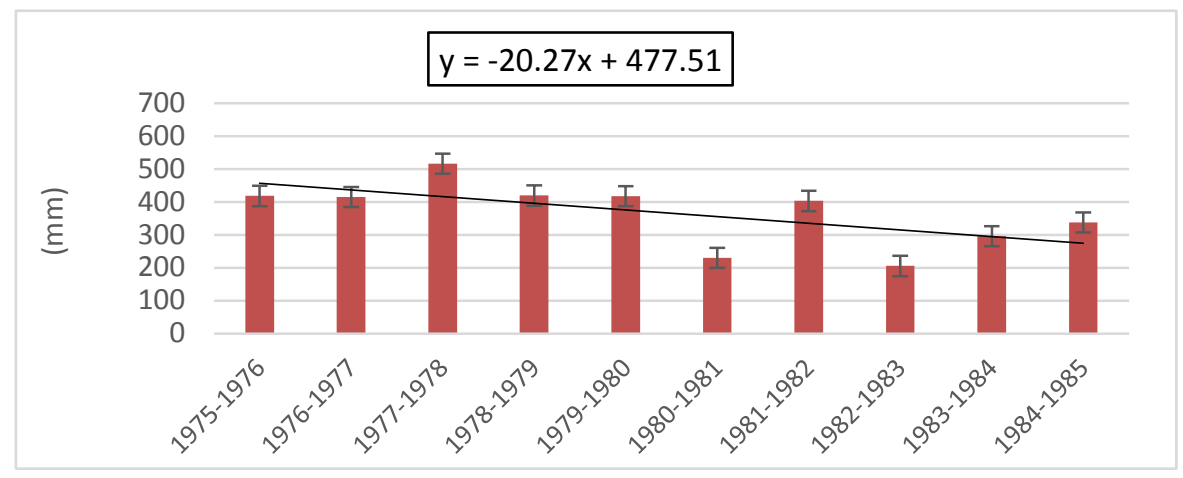

Fig. 12. Evolution of the interannual mean rainfall over the period 1975-1985 of the catchment basin $\mathrm{CO}$

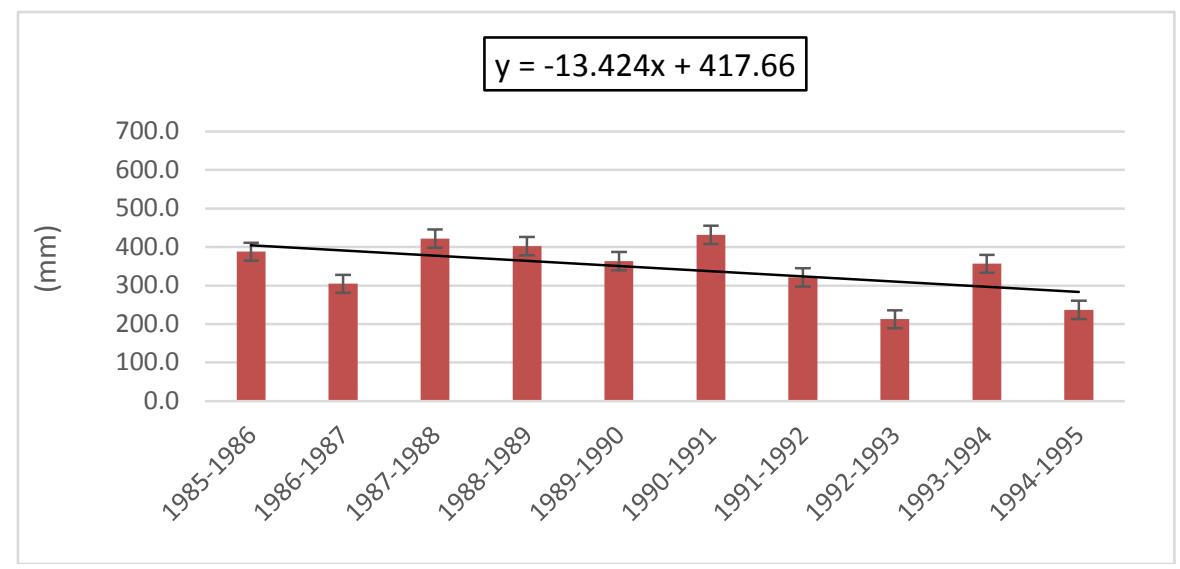


Fig. 11. Evolution of the interannual mean rainfall over the period 1985-1995 of the catchment basin $\mathrm{CO}$

Fig.

$$
y=-12.022 x+459.18
$$

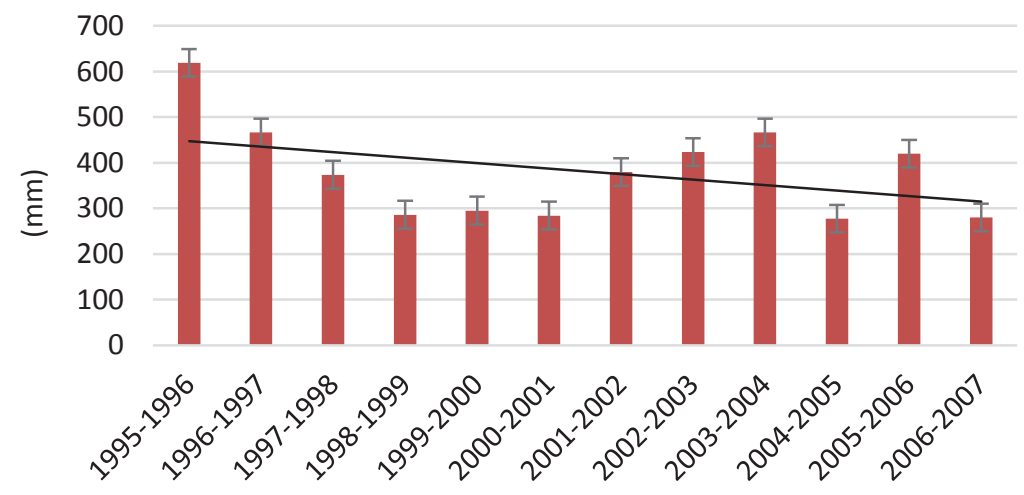

Evolution of the interannual mean rainfall over the period 1995-2007 of the catchment basin CO

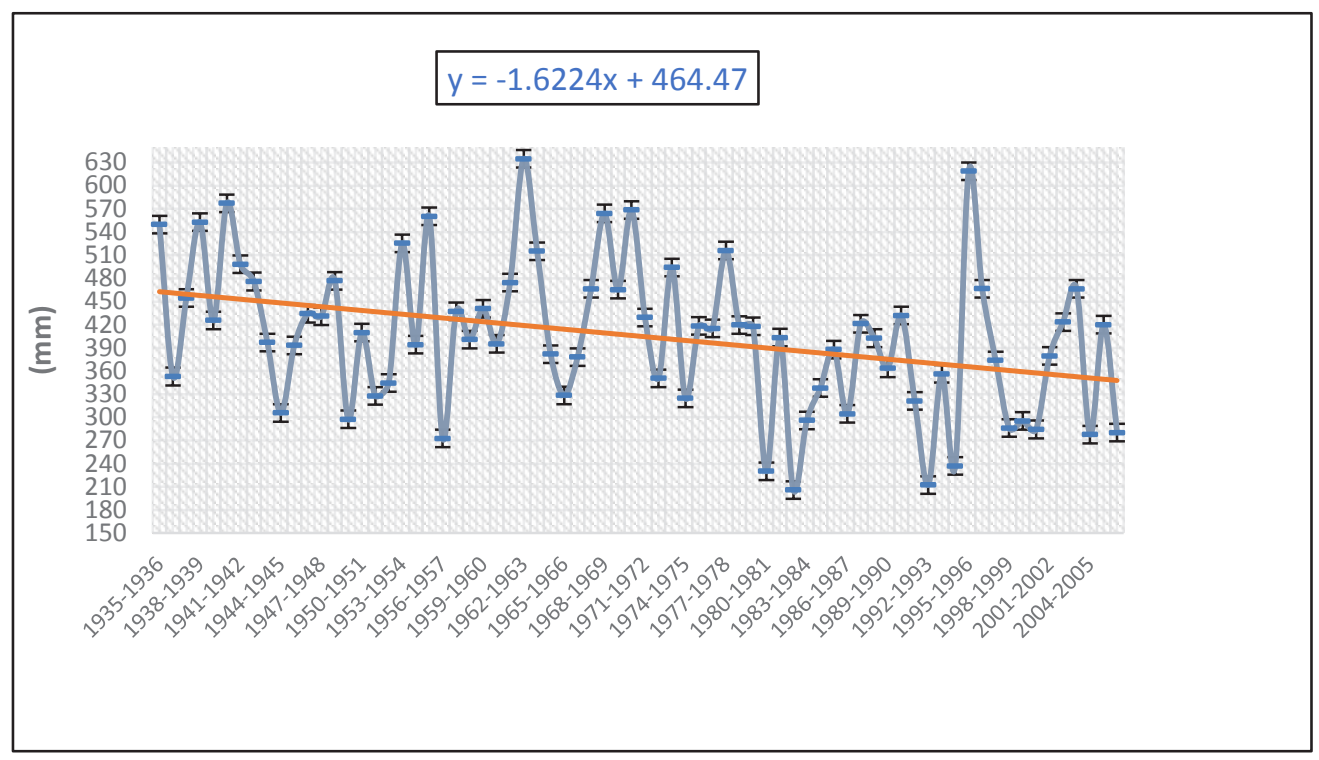

Fig .14. Evolution of the interannual mean rainfall over the period 1935-2006 of the watershed CO

The Rainfall regression and mitigation of drought weather will have a negative impact on runoff and water resources in the central Oum Er Rbia watershed. 
Table 2. Station

\begin{tabular}{|c|c|c|c|}
\hline Station & $\mathrm{X}$ & $\mathrm{Y}$ & $\mathrm{Z}$ \\
\hline $\begin{array}{c}\text { Dchar El } \\
\text { Oued }\end{array}$ & 4525501 & 231550 & 591 \\
\hline $\begin{array}{c}\text { Mechra } \\
\text { Eddahk }\end{array}$ & 394975 & 204720 & 406 \\
\hline Taghzirt & 423900 & 205600 & 565 \\
\hline $\begin{array}{c}\text { Moulay } \\
\text { Bouzekri }\end{array}$ & 401310 & 207400 & 431 \\
\hline $\begin{array}{c}\text { Ouled Sidi } \\
\text { Driss }\end{array}$ & 338950 & 192600 & 336 \\
\hline \begin{tabular}{c} 
Taghzout \\
\hline
\end{tabular} & 460950 & 235700 & 974 \\
\hline
\end{tabular}

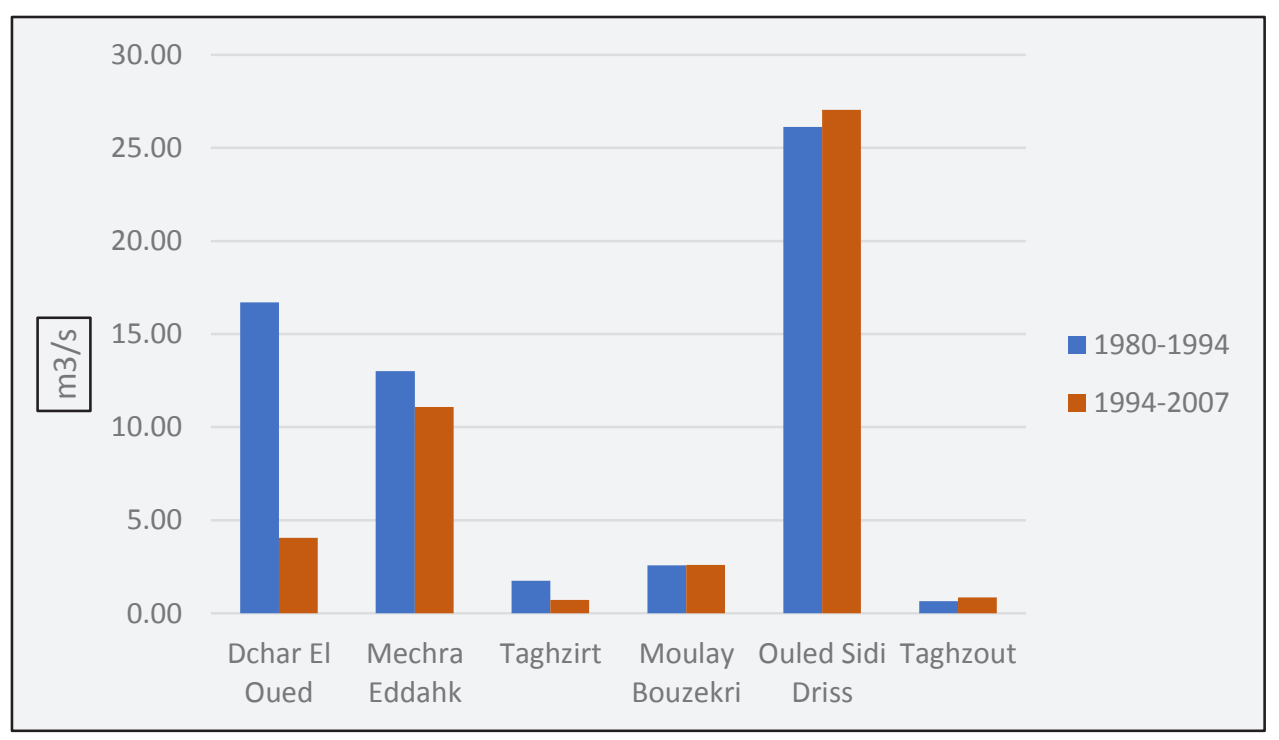

Fig. 15. Interannual average flows between two periods

\section{Discussion}

Observed climatic trends, calculated over the period 1935-2007 and reported in the study, indicate the following: 
On an annual basis, changes in precipitation were not significant and varied from one region to another.

On the other hand, spring rainfall declined significantly in the northern part of Morocco at a rate of $0.5 \mathrm{~mm} /$ day per decade

That the area experienced an average annual rainfall reduction of $70 \mathrm{~mm}(20 \%)$ over this period compared to $1940-1980$. The area is a hydraulic region that is already experiencing a water deficit. The sharp decline in water supplies since 1980-2007 (by 40\% compared with 1940-1980) and the increase in demand and water degradation by different forms of situation.

The annual average flows measured at the central Oum Er Rbia stations were reduced by considerable hydrological deficits ranging between 40.8 and $49.5 \%$.

Climate change forecasts for this region point to an increase in global warming by 2030, with increased losses due to evaporation and evapotranspiration. According to these forecasts, precipitation levels are expected to stagnate or decline slightly compared to the current situation.

The region's water scarcity and recurring droughts will also be part of the region's hydroclimatic landscape for the next 20 years.

The adaptation strategy of the region's water resources management in the face of climate change must consider this new hydro-climatic situation.

\section{References}

1. G. Wang, J.Zhang, DOI 10.1007/s11027-015-9664-x, (2015).

2. Y. Tramblay, W. Badi ,82-83 (2012) 104-114, (2012).

3. J. Schilling, P. Freier, 156 12- 26, Ecosystems and Environment (2012).

4. T. Ou, D. Chen, HW. Linderholm, Journal of Meteorology \& Oceanography 65.513931399, (2013).

5. W. Liu YLi, J. Zhou, Journal of Acta Meteorologica Sinica (in Chinese), 72.2 277290, (2014)

6. A. Voldoire, E. Sanchez-Gomez, Journal of Climate Dynamics, 40.9-102091-2121, (2013).

7. IPCC (2007) Climate change, (2007)

8. IPCC (2008) Climate Change and Water, (2008)

9. IPCC (2013) Climate change, (2013)

10. IPCC (2014) Climate change, (2014) 